\title{
INTROSPECCIÓN Y CONCIENCIA ECOLÓGICA EN CEREMONIAS DESDE LA LLUVIA DE CARLOS MANUEL VILLALOBOS
}

\author{
Insight and environmental consciousness in \\ Ceremonias desde la lluvia by Carlos Manuel Villalobos
}

Mayela Vallejos Ramirez*

\begin{abstract}
RESUMEN
En este trabajo, analizaremos la relación que existe entre la voz poética, la naturaleza y la cultura bribrí. En este poemario, el poeta se encuentra en un proceso de búsqueda espiritual para re-encontrarse consigo mismo y con sus raíces. Por esta razón, encontramos una voz poética inquisidora que se cuestiona cuál es su lugar en este mundo y sobre todo cuál es su responsabilidad como poeta-chaman. La relación del ser humano con el cosmos es relevante en estos poemas porque es lo que nos permite comprender por qué para el poeta escudriñar en la cultura bribrí es sumamente importante. Se analizan dos o tres poemas de cada apartado para mostrar cómo cada sección está intrínsecamente relacionada la una con la otra porque el poeta empieza con su propio génesis para terminar con unos poemas de corte apocalípticos en donde se muestra la posible destrucción del mundo que heredamos de nuestros ancestros, si no modificamos nuestra relación con la naturaleza.
\end{abstract}

Palabras clave: naturaleza, bribrí, cosmogonía, introspección, ceremonia.

\begin{abstract}
In this essay, we analyze the relationship between the poetic voice, nature and the Bribri culture. In this collection, the poet is in a process of spiritual re-quest to find himself and his roots. For this reason, we find an inquisitive poetic voice that questions his place in this world and especially his own responsibility as a poetshaman. The relationship between human beings and the cosmos is relevant in these poems because it is what allows us to understand why is so important for the poet to scrutinize through the Bribri culture. Two or three poems in each section are analyzed to show how each section is intrinsically linked with each other since the poet begins with its own genesis to end the collection with apocalyptic poems where the possible destruction of the world we inherit from our ancestors will happen if we do not change our relation with nature.
\end{abstract}

Key Words: nature, bribrí, cosmogony, introspection, ceremony.

Colorado Mesa University, Profesora catedrática. Estados Unidos.

Correo electrónico: mvallejo@coloradomesa.edu

Recepción: 04/03/2014. Aceptación: 30/06/2014. 
La poesía es el lugar donde todo sucede. A semejanza del amor, del humor, del suicidio y de todo acto profundamente subversivo, la poesía se desentiende de lo que no es su libertad o su verdad. Decir libertad y verdad y referir estas palabras al mundo en que vivimos o no vivimos es una mentira. No lo es cuando se le atribuye a la poesía: lugar donde todo es posible.

Alejandra Pizarnik, 1962

Para el poeta costarricense Carlos Manuel Villalobos, la poesía es ese lugar donde todo es posible. Es el medio por el cual la voz poética se re-encuentra con sus raíces, con sus ancestros y consigo mismo. Dentro de este mundo idílico, el poeta encuentra una profunda libertad que le permite trasmitir a través de sus poemas una experiencia vital que surge de las comunidades ancestrales que lo asedian y de los valores esenciales recibidos en el núcleo familiar. Por esta razón, el idilio en Ceremonias desde la lluvia (1995) juega un papel sumamente importante, ya que según Luis Beltrán "El idilio supone una esfera específica del patetismo, la esfera reservada a los valores familiares puros... El valor familiar había sido la piedra angular del mundo de las tradiciones y llevaba aparejado la noción de tiempo eterno, esto es, estático, axiológico y reversible" (La imaginación literaria 2002: 125). En este poemario, las tradiciones y la nostalgia por el pasado denotan un lugar prevalente porque es la manera en que afirma la voz poética su lugar en este mundo. Coincidimos con Beltrán cuando afirma que existe una distinción entre el patetismo y lo quimérico. En Villalobos, ese espacio idílico es una muestra de valores familiares del patetismo ya que presentan conflictos, dificultades para ser aceptados abiertamente como le habían sido impuestos, lo que lleva a la voz poética a cuestionarlos y a rebelarse ante ellos. Este dilema es lo que le permite al poeta preguntarse cuál es su relación personal con el cosmos, con el mundo que lo rodea: "El tiempo de la desigualdad todo lo cambia y las generaciones futuras deben prepararse para vivir en su propio tiempo, renovando los valores familiares que han heredado" (Beltrán 2002: 126). Esto es precisamente lo que plasma Villalobos en su poemario. Escudriña, cuestiona, compara el pasado con el presente, se rebela, se asombra, se integra a la naturaleza humana para reencontrarse con un universo que se encuentra herido por todos los cambios ambientales, económicos, sociales y culturales. También nos deja claro que se hace necesario volver nuestra vista a las culturas amerindias para reencontrarnos con un aspecto fundamental de nuestra cultura que ha quedado soterrado, olvidado o menospreciado por las sociedades modernas que se alejan cada día más de lo esencial del ser humano que tiene que ver con su relación con la tierra y la naturaleza. Los procesos globalizadores nos alejan cada día más de nuestras raíces ancestrales y sobre todo de los conocimientos básicos de supervivencia. Esto unido a una visión europeizante que ha prevalecido en nuestras sociedades desde la conquista hace que se mire con menosprecio la herencia indígena. La voz poética quiere recuperar esta herencia y demostrar que la actitud colonizadora debe desaparecer para dar paso a una mayor autenticidad que revele verdaderamente quiénes somos. El sujeto poético rompe con lo trasmitido no solamente en el núcleo familiar, sino también con lo heredado de las instituciones sociales que a través de su formación social habían impuesto en su ser y en su actuar.

Por lo tanto, Ceremonias desde la lluvia (1995) es un poemario sumamente introspectivo en donde la voz poética nos hace un recorrido por su propio génesis, por su relación con la naturaleza, por los mitos bribrí cabecar y por el futuro de nuestro mundo. Es realmente una epifanía en donde el poeta manifiesta una necesidad de conocer sus raíces y de afianzar su compromiso con el mundo en su quehacer poético. Por esta razón, su relación con el pasado es fundamental. Por un lado, rompe con lo impuesto por la cultura occidental. Y por otro lado, ambiciona descubrir la herencia ancestral indígena porque la encuentra más a fin con su manera de percibir el universo. A través de sus palabras, él busca transmitir ese conocimiento que nace de su ser interior que le permite crear una gran armonía con su entorno. Para efectos 
de este trabajo, realizaré un acercamiento general al poemario y luego me enfocaré en algunos poemas específicos que muestran como la cultura bribrí ha marcado la visión del poeta con relación a su entorno social y su relación con la naturaleza.

Quiero empezar por el título del poemario Ceremonias desde la lluvia. La palabra ceremonia nos remonta a un acto solemne que lleva implícito normas o ritos de tipo religioso o tradiciones culturales. Por esta razón, han acompañado al ser humano casi desde el inicio de la creación y permitieron que acontecimientos cotidianos se convirtieran en algo sumamente especial. En el caso particular de este libro, estas ceremonias están relacionadas con las tradiciones bribrí cabecar desde una perspectiva cosmogónica. Ya que la voz lírica pretende dar su respuesta al origen del universo enlazado con su propio origen, no simplemente como hombre, sino también como poeta-chamán Siwabra del grupo de los Tsokör, conocido como el cantor mágico de las ceremonias. Estos chamanes especializados tenían y tienen la responsabilidad de trasmitir a través de sus cantos ceremoniales la sagrada historia antigua. Pues su linaje fue creado por Sibö para preservar y trasmitir el conocimiento. Su función como Siwabra, en este caso le permite, al poeta interpretar la realidad que le ha correspondido vivir para denunciar de una manera personal el deterioro del universo que hemos heredado: "Me asomo por la ventana a mirar/ el siglo XXI/ y su pesado tercer milenio/ surgiendo del posmodernismo" (Villalobos 1995: 62). El poeta no se detiene simplemente a honrar la naturaleza misma sino que por el contrario lanza un clamor de súplica por el atropello que ha sufrido nuestro mundo ante la apatía, la inconciencia, la indiferencia de unos cuantos que dejan que la tierra agonice irremediablemente: "Un día de tantos vamos a ver un pájaro con el vuelo de pique, / un río ahogándose de sed entre las piedras,/ o el aire buscando un barranco para tirarse. (Villalobos 1995:63). Nótese las imágenes apocalípticas usadas por la voz poética en su intento por despertar una mayor conciencia en la humanidad que se muestra indiferente ante los cambios climáticos y al deterioro del planeta. Su función como Siwabra es "la interpretación armónica de la naturaleza en todas sus facetas: tiempo, espacio y ser" (Sibaja 1986). Por lo tanto, tiene la obligación de denunciar la pérdida de esa armonía antes de que solo prevalezca el caos y con ello la destrucción del propio ser humano al haberse truncado la relación con la madre naturaleza:

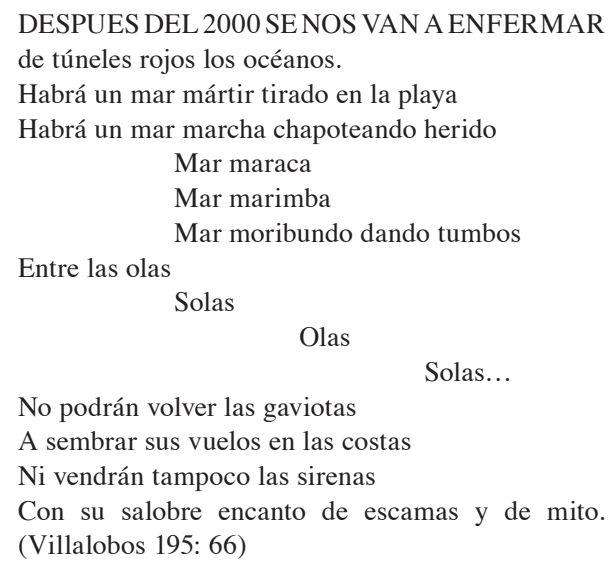

El poeta se vale de la personificación para crearnos una imagen sumamente poderosa de un océano enfermo, moribundo por toda la contaminación que los seres humanos hemos creado a través de los tiempos. La voz poética enfatiza la catástrofe que se avecina por medio de la anáfora usada en varias estrofas para crearnos esa imagen de mar agonizante, mar moribundo que se va quedando solo, solo como nos lo muestra la interesante onomatopeya usada en este poema en donde no solamente nos hace sentir el susurro del mar sino también el declive hacia donde se dirige el océano sino se pone un alto a su contaminación.

El otro elemento sumamente interesante en el título del poemario es de donde procede este canto. Apréciese que la preposición usada es "desde", la cual implica origen. Estas ceremonias nos dan un punto de referencia porque nacen desde "la lluvia". Elemento vital para las culturas amerindias, a la cual le guardaban gran veneración porque era dador de vida. La lluvia ejerce su acción fertilizadora que impulsa el crecimiento de las cosechas que 
proporcionarán sustento a las personas. Por lo tanto, todas las tribus amerindias tenían dioses consagrados a la lluvia como Tlaloc, Chac Mool, y Kon solo para mencionar unos cuantos. Ahora bien con los cambios climáticos producidos por el recalentamiento global, la lluvia se ha convertido en un elemento sumamente destructivo ya sea por la abundancia de agua o la escasez de la misma. En fin, estas ceremonias están intrínsecamente relacionadas con la lluvia porque este elemento es una parte fundamental de las culturas y gran parte de su desarrollo depende de ella. Dos de los subtítulos en que está divido el poemario también reflejan el uso de proposiciones con relación a la lluvia. Los poemas en el segundo apartado están "cerca" de la lluvia y en el tercero están "al otro lado de" la lluvia. El gran símbolo en este poemario es la lluvia y la relación que existe entre este elemento y el sujeto poético es vital para la comprensión de estos poemas.

Ahora bien, el poemario está divido en cuatro partes, lo cual también se nos hace muy significativo si tomamos en consideración la influencia de la cultura bribrí que predomina en estos poemas. Cuenta la historia que el gran maestro de las ceremonias, el chamán llamado BIKAKRA elegido por Sibö, después de crear al mundo, iniciaba la ceremonia dando "cuatro potentes golpes de su intocable bastón ceremonial en la tierra" (Sibaja 1987). Este paralelismo nos lleva a pensar que siguiendo esta tradición, el poeta ejecuta sus cuatro golpes al dividir su poemario en cuatro secciones que plantean una temática que va desde su propio génesis hasta terminar con un apocalipsis esperanzador.

El poemario en general está planteado con un doble discurso porque tres de las secciones están introducidas por un epígrafe creado por el mismo poeta que se asocia con su vida personal o con las tradiciones ancestrales familiares o bribrí. Los epígrafes son muy interesantes porque reflejan el lado más crítico del sujeto poético por encontrarse en primera persona. Algunos tienen un tono sarcástico o irónico que critican aspectos de la sociedad. Mientras que otros nos permiten conocer sucesos más íntimos de la niñez del poeta. En fin, la función de los epígrafes en este poemario es sumamente interesante porque fortalece el sentir y actuar del poeta.

La primera parte intitulada Iniciación, nos remonta al nacimiento del poeta mismo como se puede apreciar en el poema que abre la colección:

\section{SU NACIMIENTO RESULTÓ COMO}

TODAS LAS SIEMBRAS:

millones de hechiceros suicidas

iban corriendo por las trompas de Falopio

y allá a la distancia

vieron una placenta de guayaba

con una ventana abierta.

Pero entró el más ágil

Los demás, mientras morían, oyeron un encuentro

de antiguas lluvias sudando el universo. (Villalobos 1995:13)

Desde el inicio se puede valorar la relación que existe entre el poeta y la naturaleza. En este poema se pueden apreciar las imágenes del mundo tropical y la cultura bribrí que utiliza para describir su fecundación. El epígrafe en este poema es muy significativo porque es como una especie de queja por haber nacido en una sociedad que inventa mitos pero no es capaz de entender la naturaleza que la rodea y menos aún la tierra que heredó. Prefiere crearse otras explicaciones que los asemejen más a otras culturas consideradas como superiores porque aún se vive marcado por el colonialismo, que aceptar que somos hijos del trópico.

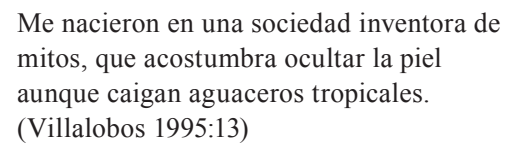

El intento de autodefinición es patente en los poemas de esta sección. Son poemas cargados de una fuerte crítica hacia la sociedad occidental en que le tocó nacer. Se niega a cargar con un peso ancestral que en vez de liberarlo lo ata a principios que no comparte:

El oficiador toma entre sus dedos una cruz, lanza una bocanda de salmos al aire y declara al recién untado de Dios: católico, apostólico y romano. 
Pero cuando todo parece color de colibrí le anuncian

que el húmedo ritual no perdona de la deuda per cápita.

El niño debe a los bancos internacionales

100 años de sudor. (Villalonos 1995: )

En los primeros versos podemos ver como la voz poética critica que le hayan impuesto una religión como lo hicieron con los ancestros durante la colonización. Desde su nacimiento es condenado por ser pecador y "deciden perdonarlo/ y le mojan el pelo/ en el nombre de Dios del Hijo y del Espíritu Santo" (Villalobos 1995:15) para que quede libre de una culpa de la cual no tiene la más mínima conciencia. De una forma sarcástica, el poeta se rebela ante una religión heredada con la cual él no siente tener ninguna relación. En el segundo verso, nos plantea otro aspecto colonizador moderno que es la deuda per cápita que heredamos de los bancos internaciones aunque las personas no sean responsable directos de las inversiones o transacciones económicas que los políticos hacen en nombre del pueblo. La voz poética protesta ante la incómoda herencia que le han querido hacer responsable desde su nacimiento.

Siguiendo su proceso de búsqueda personal, nos encontramos como Villalobos nos deja saber que su nacimiento viene marcado por los dioses: "Es un simio hecho para poeta por el don de las metáforas" (Villalobos 1995:14). En otras palabras viene predestinado para ser profeta-chaman. Paulatinamente, va descubriendo la sensibilidad de cuál ha sido dotado por los dioses "Los cuentos me buscaban en la noche/ dormía conmigo, /querían que alguien los dijera" (Villalobos 1995:21). Esta inclinación poética pasa desapercibida por sus familiares, especialmente por sus padres que no comprenden la sensibilidad con que ha nacido su hijo, como se aprecia en esta estrofa:

\footnotetext{
Tal vez por tanto tizón llamándola en la cocina ella nunca supo que el niño orinaba boca arriba para mojar las nubes y llover desde la tierra. (Villalobos 1995: 22)
}

Con el transcurrir de los años su conexión con la naturaleza se va perdiendo y por ende Sibö ya no puede compartir con él "la historia de su otro pueblo" (Villalobos 1995: 30). Su educación formal lo llenó de otros conocimientos y le procuró otras inquietudes en esa búsqueda laberíntica personal:

\author{
Lloró las primeras sílabas \\ pero se fue llenando \\ de sorpresas: que Salgari, que Verne, que Lovato. \\ Y el niño dejó que el trompo bailara en los \\ recuerdos, \\ Mientras seguía subiendo \\ Por las lomas a buscar un dios en los jarales. \\ (Villalobos 1995: 31) \\ El segundo apartado se denomina Danza
} ceremonial cerca de la lluvia. En estos poemas, la voz poética nos presenta mitos, creencias, ceremonias, costumbres familiares y locales. Estos poemas nos acercan a las ceremonias ancestrales o a las costumbres que marcaron la existencia del poeta. Por esta razón, encontramos una variedad temática que se remonta a evocaciones infantiles del poeta mismo. El poema "Ritual de arcillas" nos retrocede a una tarde lluviosa en donde la familia o los amigos se sentaban a degustar una rica taza de aguadulce para luego crear con la imaginación un mundo mágico como resultado de esa lluvia fructífera que les inspiraba cantos. Es un poema muy familiar cargado de una dosis de emotividad. Casi se puede sentir la fraternidad que se da entre los miembros de la familia que disfrutan tranquilamente de la naturaleza y sus riquezas espirituales:

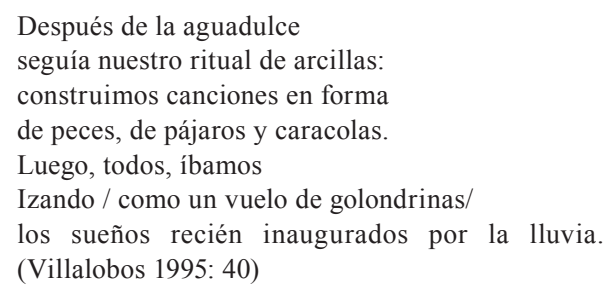

El último poema de esta sección retoma la nostalgia y sentimentalismo del poema anterior. A diferencia, en este poema encontramos a Villalobos evocar su época escolar y como ésta 
marcó un momento muy especial en su vida. Es un tiempo vital porque le permitió darle alas a la imaginación y crearse un mundo maravilloso:

Durante el viaje diario de dos kilómetros

El vuelo de las mariposas eran entonces papalote

Y un trillo de hormigas era un río de sueños

Bajando por las cuevas. (Villalobos 1995: 41)

Aunque algunos de estos poemas denotan una carga biográfica muy fuerte comprendemos que es más un biografismo sentimental que reflejan parte de su vida para explicar otros aspectos de su obra poética a través de ellas como lo son su relación con el mundo social, político y económico.

Este aspecto se puede observar en el siguiente poema "Natalicio nublado" en donde el poeta contrasta las tradiciones navideñas de su hogar o de su pueblo con las foráneas. Estas tradiciones extranjeras irrumpen en las concepciones auténticas que crearon la cultura hispana para dar paso a concepciones que no podemos realmente comprender porque no son parte de nuestra historia:

\footnotetext{
En mi casa no había ciprés en el portal, ni muñeco de nieve, ni trineo con un Merry Christmas en la ventana. Por eso/quizás/ el niño Dios pasaba silvando por detrás de los itabos O tal vez es que nunca le gustó aquel aroma de tamales y fogón. (Villalobos 1995: 36)
}

En estos versos, la voz poética se vale de imágenes que contrastan ambas tradiciones: la costarricense con la anglosajona para mostrarnos el antagonismo que se produce entre estas culturas. Se aflora la idea que el imperialismo, no solo controla aspectos políticos sino que impone tradiciones que en cierta medida debilitan las culturas colonizadas. En este verso se pueden ver los símbolos de ambas tradiciones en contra posición como por ejemplo, "ciprés /portal, niño Dios/trineo (alusión a Santa Claus)." De la misma forma que en los otros poemas de este apartado, la voz poética evoca aspectos importantes de su niñez. Esa voz poética infantil asevera que al niño Dios no le gustaba el olor a "tamales y fogón". En otras palabras no le gusta el olor a la pobreza, al tercer mundo que no sabe adornar sus casas con los símbolos propios del primer mundo. Lo irónico y cruel es que los niños se quedan esperando los regalos que supuestamente debían de recibir para las navidades porque el niño Dios pasó de lejos ignorando los sueños de los niños entre los que se encuentran el de nuestro sujeto lírico que se muestra sumamente desilusionado por no haber recibido el anhelado juguete:

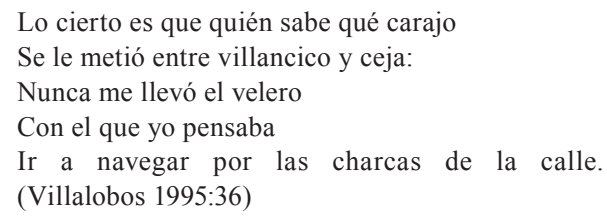

La tercera parte del poemario Danza ceremonial al otro lado de la lluvia, muestra un despertar de la voz poética mucho más maduro y consciente de su entorno. Se percata que la vida que ha vivido no es realmente suya porque siempre ha seguido los pasos que otros ya le habían marcado: "Luego, como todos, / salgo a repintar las huellas de los otros" (Villalobos 1995: 47). El poeta vuelve a rebelarse contra las imposiciones de la sociedad que no le permite ser un ser único. En este mundo en realidad no existe libertad sino sutiles imposiciones. Se le ha impuesto como actuar, como pensar, como dirigir su vida. Se espera que se acople a las expectativas socioculturales de un buen ciudadano. Paulatinamente, el poeta descubre que es muy difícil romper con las exigencias de este mundo:

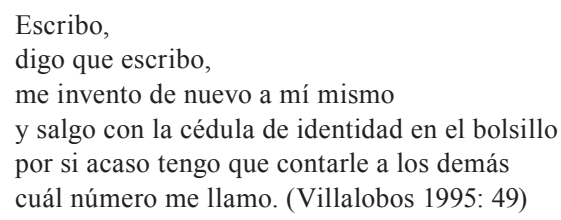

Claramente se puede apreciar la contraposición que se genera en estos versos. Por un lado, el poeta es capaz de reinventarse, de crear otra versión de sí mismo. Sin embargo, no puede salir a la calle sin su cédula de identidad que le acredita ser la persona que dice ser. Entonces, la libertad se ve coartada porque no es quien el quisiera ser pero el individuo que 
reconoce la sociedad. Por esta razón, reconoce que es "incapaz de quitarse el himen/ de un solo tajo, /o una sola borrachera (Villalobos 1995: 49). Aunque las personas no lo aceptemos vivimos impuestas a las leyes sociales que rigen a los pueblos.

Poco a poco, Villalobos va encontrando su camino y rompe con las tradiciones heredadas para adoptar unas que vayan más acorde con su manera de percibir el mundo: "Dejaré claro que no soy cómplice/de los que buscan un solo dios" (Villalobos 1995: 50). Nos confiesa abiertamente que a él no le interesa que lo relacionen con la cultura occidental, ni con religiones impuestas. Por eso, se declara más hijo de Sibö que de Jehová. Se encuentra más a gusto con los ancestros bribrí que con la sociedad actual aunque reconoce la incapacidad de asimilarse completamente a la cultura indígena por la época en que le tocó nacer:

\footnotetext{
Aquí nací, sobre el fantasma de los huertares sobre los huesos nunca de una lengua que murió sin un solo archivo donde poder mirarse la sangre

Aquí nací, junto a las piedras anónimas

Y las vasijas rotas de otro siglo,

Junto a las iguanas que se esconden de la extinción. (Villalobos 1995: )
}

La voz lírica nos expresa que a pesar de que ya no tiene forma de recuperar la historia de ese pueblo que fue eliminado durante la colonización, él quiere rescatar parte de esa historia antes que se extinga completamente. Desea trasmitir esa herencia a las nuevas generaciones para que no olviden sus orígenes autóctonos. Aquí Villalobos declara que le interesa poco la historia occidental porque ésta no forma parte de su historia personal, ni le ayuda a entender su mundo. Es evidente que para Villalobos la historia de Latinoamérica es mucho más significativa que la historia impuesta por los vencedores que borraron de tajo las contribuciones de los pueblos que habitaban esta parte del mundo antes de su llegada:

A mí poco me preocupa Atila

y la emboscada de Bonaparte en Waterloo.

A mí me interesa más

el nopal del águila

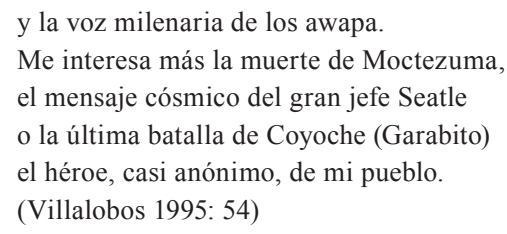

Esta declaración nos recuerda el poema de Nicolás Guillén "Problemas del subdesarrollo" en dónde Guillén insta al latinoamericano a interesarse más por la historia de Latinoamérica que por los acontecimientos europeos. Le exhorta a que se sienta orgulloso de sus raíces y que no olviden hablar español. En el caso de Villalobos, el poeta hace una declaración mucho más personal. Él ha tomado la resolución de centrar su vida más en la historia amerindia que en la historia colonizadora que se les impuso a los pueblos americanos. Sin embargo, ambos testimonios reclaman por una mayor autenticidad por parte del pueblo latinoamericano que ha permitido que se le imponga una manera de pensar. Y peor aún que se le ha hecho creer que solo lo extranjero venido del primer mundo vale la pena. Por eso, Villalobos ansia encontrar la iluminación que le permita ver más allá de lo que su formación familiar, social y formal han creado dentro de él:

\section{QUIERO MATAR ESOS ZANCUDOS DE LA MEMORIA, \\ Apuntar la vista más allá del gavilán \\ Y poco a poco irme quedando despierto. (Villalobos 1995: 56)}

El último apartado Danza final para exigir que no volteen el último aguacero cierra con elementos de carácter apocalíptico y con el reclamo ancestral por recuperar la tierra y sus elementos naturales. El subtítulo de este compendio deja claro el objetivo de la voz poética, el cual es evitar que terminen de destruir la tierra que heredamos. Villalobos, en su papel de poeta-chamán nos recuerda que no podemos menospreciar a la naturaleza porque somos una parte fundamental de ella. Por este motivo, abre esta última sección con un epígrafe del gran jefe de los pieles rojas: 
La tierra no pertenece al hombre; el hombre pertenece a la tierra. Esto sabemos, todo va enlazado, como la sangre que une a una familia. Todo va enlazado todo lo que le ocurra a la tierra, les ocurrirá a los hijos de la tierra.

Seattle (1854, jefe de los pieles rojas: 59)

Se retoma en este apartado la conexión que existe entre tierra y ser humano. No pueden separarse porque están enlazadas y lo que le ocurra a la una le ocurrirá a la otra irremediablemente. Algunos se estos poemas nos muestran los destrozos que le hemos causado al planeta. Presenta imágenes terribles de la destrucción del planeta como un sueño premonitorio:

\footnotetext{
Ojalá que no, que sea solo

una pesadilla de conjeturas pudriéndose.

Pero yo lo he visto en el verde sin verde en mi cara. Ojalá que no

que no venga el hacha a cortarnos la mañana, que no vengan los misiles a matar la lluvia, que no vengan los aviones

a secuestrarnos la sonrisa. (Villalobos 1995: 64)
}

Estos versos nos muestran la aprensión que sufre el poeta al imaginarse la posible destrucción del planeta. Sin embargo, él guarda la esperanza de que algo suceda que pare con lo inevitable. Nótese el uso de la anáfora para enfatizar su deseo por un mundo mejor. Sin embargo, el uso de los verbos en el subjuntivo nos deja la sensación que la decisión la tienen que tomar otros que son probablemente los que tienen el poder. De cierto modo también nos hace responsables a todos por lo que le suceda a nuestro mundo. En otras palabras, sino tomamos cartas en el asunto nos vamos a quedar sin planeta. No podemos permanecer apacibles ante las decisiones que toman los líderes de este mundo o los que ostentan el poder económico. El planeta es de todos y por ende todos somos responsables por lo que le ocurra. No podemos esperarnos hasta que ya se haya muerto todo: "No quedarán zorrillos ni pericas/ subiéndose a la tarde por los guarumos" (Villalobos 1995: 67). Villalobos quiere crear una concientización en todas las personas porque todavía tiene fe en el ser humano como lo deja establecido en el poema que cierra esta colección:

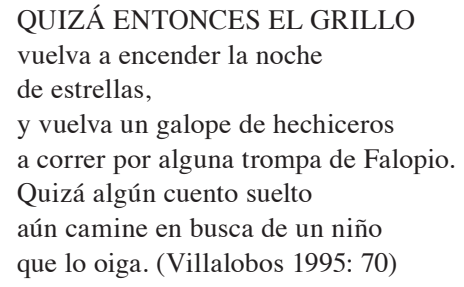

Lo maravilloso es que el libro termina con unas ideas esperanzadoras. El poeta tiene la fe que al final habrá una voz humana que clame por un renacimiento del mundo que destruimos y los dioses le regalarán a la humanidad una segunda oportunidad para que vuelva a germinar la semilla y se replante del planeta con nuevas esperanzas:

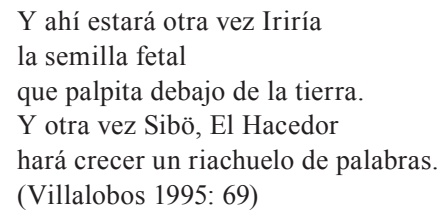

Concluimos este análisis subrayando que el elemento idílico es esencial en este poemario puesto que la identidad como plantea Beltrán surge de la tierra natal y de la tribu. Sin embargo, el crítico considera que en la modernidad el idilio puro no es posible porque el idilio familiar y territorial es incompatible con la modernidad que lo destruye. "Los aspectos esenciales de la destrucción del mundo que ha desatado la Modernidad (destrucción de la familia, de la tierra natal, del trabajo artesanal) se contraponen a un ideal de la humanidad superior, igualitaria, alegre y libre" (Beltrán 2008:15). Esa destrucción se torna apocalíptica produciendo el fin de la raza, como se puede apreciar en los planteamientos de Villalobos, en donde el futuro del mundo y de la raza humana se encamina a una irremediable destrucción. Otro elemento importante en este poemario es el aspecto autobiográfico que nos permite ver el crecimiento del poeta por las diferentes etapas de su vida. Cada uno de estos poemas nos va mostrando el desarrollo tanto físico 
como espiritual que va adquiriendo el poeta en la medida que construye su propia identidad. Nos deja ver una perspectiva muy personal que entreteje con elementos cotidianos de su entorno. En este proceso de auto-descubrimiento, Villalobos se enfrenta a un mundo que considera antagónico frente a su manera de percibir su historia y su relación con la naturaleza. El poeta abiertamente rompe con las ataduras familiares, sociales y culturales para buscar un camino propio que le ayude a encontrarse con su verdadero yo. Precisamente, ese camino lo encuentra a través de la naturaleza y la cosmogonía bribrí. El poeta descubre que tiene una mayor afinidad con las culturas amerindias que con su herencia occidental producto de un mestizaje violento y usurpador que le robó a los hijos del trópico la capacidad de familiarizarse con las culturas nativas de estas tierras. Por ende, se ha perdido la capacidad de honrar la naturaleza. En vez de esto, se ha permitido que se le ultraje a la tierra, hasta el punto que estemos a punto de destruir lo que nos queda. Por lo tanto, la voz poética trata de recobrar la armonía que existía entre los seres humanos y la naturaleza. El poeta insta al público a replantearse su relación con el medio ambiente y reparar los daños que le hemos causado a la madre naturaleza. En suma, este es un poemario que combina una búsqueda personal de carácter espiritual con una toma de conciencia sobre el medio ambiente y la necesidad que existe de concientizar a las futuras generaciones a volver sus miradas a la herencia que nos dejaron nuestros ancestros indígenas.

\author{
Notas \\ 1. Monsieur Dupont te llama inculto, \\ porque ignoras cuál era el nieto \\ preferido de Víctor Hugo. \\ Herr Müller se ha puesto a gritar, \\ porque no sabes el día \\ (exacto) en que murió Bismark. \\ Tu amigo Mr. Smith, \\ inglés o yanqui, yo no lo sé, \\ se subleva cuando escribes shell. \\ (Parece que ahorras una ele, \\ y que además pronuncias chel.) \\ Bueno ¿y qué? \\ Cuando te toque a ti, \\ mándales decir cacarajícara, \\ y que donde está el Aconcagua, \\ y que quién era Sucre, \\ y que en qué lugar de este planeta \\ murió Martí. \\ Un favor: \\ Que te hablen siempre en español.
}

\section{Bibiografía}

Beltrán, Luis. 2002. La imaginación literaria: La seriedad y la risa en la literatura occidental. Barcelona: Montesinos.

2008. El simbolismo de Juan Eduardo

Zuñiga. Barcelona: Ediciones Vitel-la

Sibaja Álvarez, Alberto. 1987. Estructura político-religiosa de los aborígenes de Talamanca. www/ monografías/com.

Villalobos, Carlos Manuel. 1995. Ceremonias desde la lluvia. San José: Editorial de la Universidad de Costa Rica.

\section{$\Theta \odot \Theta \Theta$}

Este obra está bajo una licencia de Creative Commons

Reconocimiento-NoComercial-SinObraDerivada 4.0 Internacional. 
